\title{
ANATOMICAL AND PHYSIOLOGICAL BACKGROUND PERMITTING SPATIAL ODOR SENSATION IN STYLOMMATOPHORAN MOLLUSCS
}

\author{
A REVIEW \\ TiBOR Kiss* and Nóra KRAJCS \\ Department of Experimental Zoology, Balaton Limnological Institute, \\ MTA Centre for Ecological Research, H-8237 Tihany, Hungary
}

(Received: December 01, 2015; accepted: June 09, 2016)

\begin{abstract}
Earlier experiments demonstrated that in order to place protracted tentacles and thereby olfactory receptors in an appropriate position for optimal perception of odor stimuli extraordinary complex movements are required. Until recently both large scale tentacle movements and patterned tentacle movements have been attributed to the concerted involvement of the tentacle retractor muscle and muscles of tegumentum. Recently the existence of three novel muscles in the posterior tentacles of Helix has been discovered. The present review, based on experimental data obtained by our research group, outlines the anatomy, physiology and pharmacology of these muscles that enable the tentacles to execute complex movements observed during foraging both in naïve and food-conditioned snails. Our findings are also compared as far as possible with earlier and recent data obtained on innervation characteristics and pharmacology of molluscan muscles.
\end{abstract}

Keywords: Gastropoda - tentacles - flexor muscles - neurotransmitters - modulators - olfaction

\section{INTRODUCTION}

Terestrial snails and slugs perceive odor molecules by two pairs of tentacles: the longer ones called superior tentacles (ommatophores) which are necessary for food orientation, while the shorter ones (rhinophores) called inferior tentacles and they are necessary for trailing $[9,10,66,103]$. Superior tentacles are required therefore for long-distance chemoreception and inferior tentacles generally thought to be closerange chemoreceptor organs. Chemical detection mechanisms play an important role in locating food, homing or pheromone communication and in predator risk assessment. Consequently, olfaction is unquestionably topmost in the life of gastropod molluscs. It proved to be the principal sensory modality serving essential role in behavior and learning [11, 24, 41, 76]. Observing terrestrial (stylommatophoran) snails crawling around one is immediately attracted by its head weaving and diverse movements executed by protracted tentacles. The snail scans the environment, touches objects and obstacles orienting itself by this way and at a hint of threat tentacles

\footnotetext{
*Corresponding author; e-mail address: kiss.tibor@okologia.mta.hu
} 
are quickly withdrawn. Snails are able to move its superior tentacles back and forth, sideward and up and down in order to obtain a better "view" of the milieu surrounding the animal. What is more, snails can move their tentacles separately permitting a three-dimensional perception of olfactory signals. In addition to the aforementioned "larger scale" movements, Lemaire and Chase [62] described so-called patterned movements of tentacles, which are superimposed on the larger movements. These are twitches, which are brief retractions and quivers which are rapid lateral movements without retraction. Twitches and quivers are thought to be distinct phenomena which occur at independent rates and different stimuli. It is suggested that the stereotypical movements of the tentacles, that have evolved to facilitate olfactory performance and orientation, are comparable with sniffing, tongue flicking, vibration of antennae and nose licking observed in other species. All these complex movements as part of special behaviors are in serving to increase olfactory performance by reducing for example the fluid layer on the surface of the olfactory epithelium and facilitating thereby the access of new odor molecules to the olfactory receptors by removing old ones [68]. It is suggested that at behavioral level the large-scale movements are indicative for feeding history of the snail [79], whereas patterned tentacle movements are considered to be used for active sensing the actual environment $[62,77]$. Until recently, both large-scale and patterned tentacle movements were attributed to the concerted movements of tentacle retractor muscle (TRM) and muscles of tegumentum. In general, during withdrawal the response of TRM to the incoming command is especially fast and vigorous, which evokes graded muscle response depending on the intensity of the stimulus. So it is inconceivable that the TRM and muscle cells of the tegumentum even working together are capable of executing special movements such as

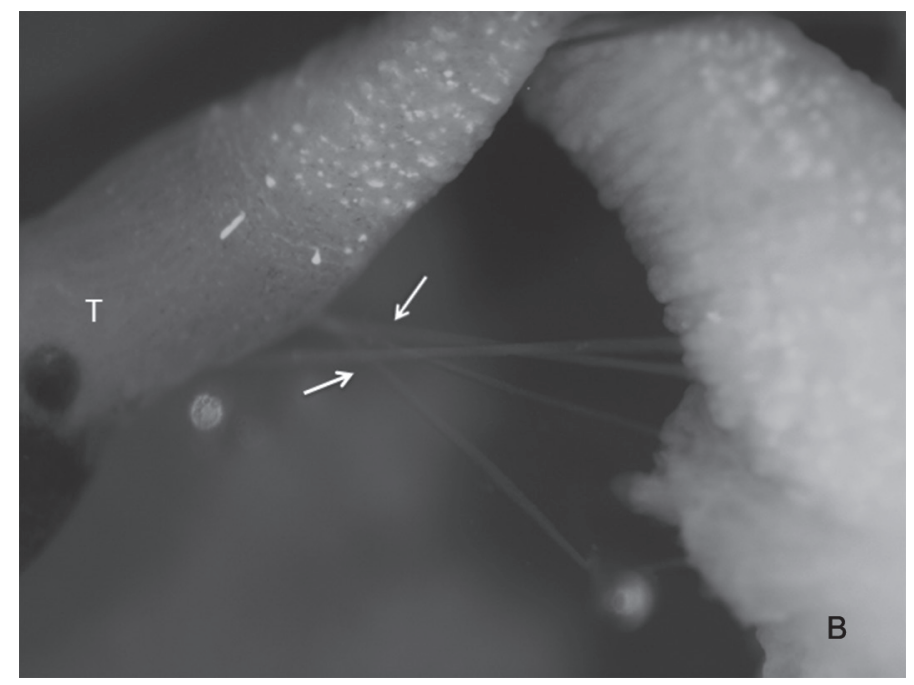

Fig. 1. The picture shows flexor muscles (lower arrow) spanning between the base (B) and the tip (T) of a tentacle. The tentacle is in inside-out position. Frequently one of the flexor muscles is ramifying (upper arrow) 
twitch and quiver. We were convinced that all kind of fine movements of the superior tentacles cannot be explained by the exclusive participation of TRM and tegumentum. In addition, even the three-dimensional movements of protracted tentacles around the basal pivot cannot be explained by the exclusive contribution of TRM and/ or muscles of the tegumentum. Recently, the anatomy of three novel muscles in the superior tentacles of Helix pomatia was described [31]. These muscles span in the tentacle from the base to the tip and always take the length of the stem which depends on the extent of hydrostatic pressure indicating that muscles are capable of contracting and extremely elongating (Fig. 1). The muscles have been called by authors as flexor muscles (FM), although according to our opinion a denomination as "string muscles" would better describe them. It is plausible to suggest that these newly described muscles play an indispensable role in executing movements such as twitching, quivering and moving around the basal pivot of protracted superior tentacles during olfactory orientation. In order to meet these demands the FMs must have a special ultrastructural and physiological organization as well as neural control. The present review summarizes the findings obtained by us so far on the ultrastructure, contractile properties, innervation and pharmacology of the FMs, and will compare them with data obtained on other gastropod muscles wherever it is possible.

\section{ULTRASTRUCTURE RESPONSIBLE FOR THE PECULIAR CONTRACTILE PROPERTIES}

Our ultrastructural studies revealed that FM can be classified as smooth muscle, because the thin and thick filaments are not arranged into sarcomeres. In the FM, mitochondria are present in large numbers and they create a central core of the muscle cells [59]. This arrangement is different from that described in most of the invertebrate animals, since in most cases these organelles are located at the periphery of the smooth muscle cells [78]. On the other hand, the arrangement of mitochondria observed in the FM is similar to the organization described in another tentacular muscle, the tentacle retractor of Limax flavus and Helix aspersa [84]. In the radula retractor muscle of the whelk, Buccinum undulatum, unusually large mitochondria packed into dense central clusters were also observed which were surrounded by large deposition of glycogen granules [75]. Directly below the FM sarcolemma, large numbers of subsarcolemmal vesicles and flattened subsarcolemmal tubules can be seen. In all the investigated molluscan muscles subsarcolemmal cisternae connected to thin reticular tubules forming dyads with the sarcolemmal membrane were observed [2]. Previous studies on invertebrates demonstrated that these structures and mitochondria release $\mathrm{Ca}^{2+}$ ions to the sarcoplasm, which is essentially required to perform muscle contraction [6,34]. Although in vertebrates the usual source of $\mathrm{Ca}^{2+}$ necessary for excitation-contraction coupling derives from internal stores, the situation in molluscs is less clear [9]. A contraction-induced release of $\mathrm{Ca}^{2+}$ from intracellular stores has been demonstrated in several molluscan muscles, such as the anterior byssus retractor muscle of Mytilus, the longitudinal body wall muscle of Dolabella, 
the radula protractor and penis retractor muscles of Busycon and Helix, respectively $[35,88,92,93,95]$. There is additional evidence that intracellular $\mathrm{Ca}^{2+}$ is involved in excitation-coupling of heart muscles of Helix $[18,47]$. However, there are several suggestions, that $\mathrm{Ca}^{2+}$ entering from extracellular space is also involved directly or indirectly in E-C coupling [72]. Since we did not observe any organized sarcoplasmic reticular system in the FM cells, it was suggested that both mitochondria and subsarcolemmal structures function as intracellular $\mathrm{Ca}^{2+}$ stores. The suggestion was verified by our physiological experiments, in the course of which caffeine was able to evoke remarkable muscle contraction even after incubating the muscle in $\mathrm{Ca}^{2+}$-free extracellular solution up to 12 hours prior to testing. The contribution of inward $\mathrm{Ca}^{2+}$ movement was also suggested because in Na-free solution both $\mathrm{K}$ - and acetylcholine (ACh)-elicited contractions were decreased [59].

The FM is composed of loosely packed muscle cells, connected to each other via long, finger-like protrusions of the sarcolemma, forming close membrane attachments, although specialized connections were not identified. Specialized connections such as nexuses and desmosomes have been reported in a variety of molluscan muscles [86]. In the FM specialized connection between muscle fibers could not be observed. Sarcolemmal protrusions may play a role in the synchronization of contractions of single muscle fibers and/or they can provide structural stability. In the muscle cells of superior tentacles of Helix aspersa and Limax flavus the presence of sarcoplasmic protrusions was also reported and it was suggested that these protrusions showing "peg and socket" arrangement may provide coordinated contractions of the whole muscle tissue [84]. In the FM similar function of the sarcoplasmic protrusions was not verified, due to the low number of these structures and lack of specialized membrane structures between them. We assume that sarcoplasmic protrusions rather contribute to the structural stability especially in case of extreme elongation of the protracted tentacles. Ultrastructural studies also revealed that the FM is considerably rich in collagenous fibers, which encompass the muscle cells. The muscle cells of pulmonate snails are usually not interconnected, but they are directly connected to the collagenous connective tissue surrounding them [64]. In echinoderm muscle a socalled "catch connective tissue" is present, wherein the collagenous fibers are able to contract and this process is controlled also by the nervous system [71]. Analogous collagen fibers can be found in the connective tissue of the gastropod columellar muscle $(\mathrm{CM})$, probably transmitting the force of muscular contraction and ensuring structural rigidity [83]. Although experimental evidence for the role of collagen fibers in the FM contraction is lacking, due to their presence in large amount it is suggested that collagenous fibers somehow support the muscle contraction. It was observed that FM has the ability to elongate to four- or fivefold compared to the length of its resting state. This can be observed when the snail is exploring the environment by moving the completely protruded tentacles into different directions in space. Thus, FM collagen together with sarcoplasmic protrusions can also be involved in the extreme extensibility of the muscle during olfactory orientation and may contribute to the force transmission. In vertebrates it has been shown that the extracellular matrix (ECM) and especially the connective tissue with its collagen plays an important role 
in the force transmission and tissue structure maintenance especially in muscle [52]. The morphology of the invertebrate smooth muscle cells varies widely among species and even within the same species. An ultrastructural study of several muscle types in the pond snail, Lymnaea stagnalis, revealed important differences between them regarding cell size, myofilament size and number, number of mitochondria, and sarcoplasmic reticulum development [80]. Seemingly ultrastructural differences along with the contractile protein composition of the muscle strongly reflect the physiological task to be performed by the specific muscle.

\section{INNERVATION}

An ultimate difference between vertebrate and invertebrate motor systems is the nature of their neuromuscular innervation. Most invertebrate muscle fibers, receive synaptic inputs from multiple motoneurons and in addition from modulatory neurons, such that significant motor plasticity can be generated at the periphery $[33,42,67,81$, 91]. Innervation of muscles of different molluscan species is usually reduced to a single naked axon contacting the muscle fiber. The nerve terminal usually lies in a groove of the muscle cell or is enveloped by the muscle cell (sarcoplasm) protrusion(s). The nerve and muscle cell membranes are closely apposed, they do not show however specializations typical for vertebrate myoneuronal-junctions. Still, these contacts present part of the ultrastructural characteristics of a chemical synapse, such as asymmetrical (presynaptic) vesicle clustering and increased electron density of the pre- and postsynaptic membranes, as it was demonstrated earlier in different muscles of Helix [14]. Typical, ultrastructurally specialized neuro-muscular contacts were only found in the ventricle of the Helix heart [16].

FMs receive rich innervation by axons of cerebral neurons branching extensively along the muscle fibers and making contacts typical for molluscs [29]. Using anterograde neurobiotin tracing we have demonstrated that FMs received nerve fibers via the olfactory (o.n.) and from the external peritentacular (ePtn) and internal peritentacular (iPtn) nerves. Fibers labeled via the o.n. were present in each one of flexor muscles (FM1-FM3) and additionally in the muscles of tegumentum, the stem and the TRM. The iPtn innervates the FM1 and a ventromedial stripe of the tegumentum located in the vicinity of the anchoring point of the muscle. The ventro-lateral branch of the ePtn innervates the FM2 and the external ventro-lateral stripe of tegumentum, whereas the dorso-lateral branch of the ePtn innervates the FM3 and the dorsal area of tegumentum [32]. Stimulation of the o.n. by a single electrical impulse elicited contraction with the same amplitude in isolated FM1, FM2 and FM3 confirming experiments done with neurobiotin that is FMs receive common innervation by o.n. Stimulation of the iPtn elicited contraction of the FM1, while stimulation of the ePtn evoked response of the FM3. However, when a train of stimuli was applied to the ePtn or iPtn weak contractions of the FM2 and FM3 were observed in addition, suggesting a possible involvement of peripheral neurons located in the digits of the tentacular ganglion (TG). Until recently peripheral motor neurons were not identified 
since the motor control of local tentacle movements without CNS was not proved. The presence of peripheral motor neurons, however, was hypothesized because it was observed that lateral flexion or quiver could be induced in isolated tentacle preparation as well [77]. Recently we have described neurons in the digits, neurites of which innervate muscle fibers both in flexor and tegumental muscles [29]. In order to reveal neuronal elements innervating FMs, neurobiotin tracing was performed via the tentacle FMs. It was observed that mostly unipolar motor neurons confined to the digits of TG innervate FM2 and FM3 muscles. Consequently, the muscles capable of eliciting quiver are FM2 and FM3. Based on these neuroanatomical results, it was supposed that part of the population of light type neurons of digits fulfill motor neuron function in the ventral and lateral digits [29].

Earlier it has already been described that the muscles (tegumentum and TRM) of superior tentacles are innervated by the o.n. and by the ePtn and iPtn [46]. The neuronal background of positioning the snail's tentacles was studied by applying retrograde Co-/Ni-lysine tracing via the olfactory and peritentacular nerves [79]. The findings revealed that distinct areas of the tegumentum are innervated by these nerves. The authors concluded that the common innervation pathway is required for tentacle withdrawal, whereas the distinct pathways are primarily responsible for bending of the protracted tentacles around the basal pivot. Stimulation of the ePt nerve evoked external lateral, stimulation of the iPt nerve induced medial downward movement of the protruded tentacle, whereas stimulation of the o.n. elicited only local movements of the tip of tentacles [79]. Based on these data it was concluded, that muscle cells of tegumentum are sufficient in generating the full complement of movements mentioned above. However, when the superior tentacles are fully protracted and stretched by the hydrostatic pressure, the ability of various part of the tegumentum to move the tentacle around its basal pivot has been questioned $[32,59]$. Our recent anatomical findings indicated that bending of the protracted posterior tentacles in different direction around the basal pivot needs, first of all, the contraction of the FMs. It cannot be excluded, however, that parallel contractions of various regions of the tegumentum may give assistance to FMs. Central control of FMs was investigated by applying a paired $\mathrm{Co}$ - and Ni-lysine tracing via the olfactory and $\mathrm{ePt}$ and $\mathrm{iPt}$ (on+ePt, on $+\mathrm{iPt}$ and $\mathrm{ePT}+\mathrm{iPt}$ ) nerves [32]. It was revealed that neurons innervating the tentacle and FMs are clustered into eight groups (g1-g8) in the cerebral ganglion (CG). In $\mathrm{g} 1, \mathrm{~g} 4$, g6 and $\mathrm{g} 7$ clusters all the three innervating nerves are represented. In $\mathrm{g} 3$ and g5 only the iPT and ePT nerves, whereas in the g2 the o.n. is dominantly represented, respectively. Neurons of the g8 could be labeled only through the ePtn. The diameter of most of the labeled neurons of clusters is less than $30 \mu \mathrm{m}$. Exception is represented by g3 cluster in the medial part of the mesocerebrum where mostly $60-70 \mu \mathrm{m}$ cells are labeled. Neurons of the g3 and g5 clusters are labeled through Ptns exclusively, therefore it can be suggested that these cells are motoneurons. The functionally and morphologically identified solitary FMRFamidecontaining C 3 neuron is labeled via the olfactory and both Pt nerves, and the participation of this cell in the tentacle withdrawal reflex and tentacle graded retraction was described $[12,82]$. We have observed that the position of neurons labeled via the 
olfactory and Pt nerves fall into the areas where neurons are located innervating the head areas. Unfortunately the retrograde labelling through innervating nerves did not allow selecting motoneurons innervating exclusively the FMs. Most of the labelled neurons of the $\mathrm{g} 1-\mathrm{g} 8$ groups are not studied by electrophysiological techniques; hence their functional role in FM regulation remains speculative. The innervation pattern suggests that FM is analogous to other molluscan muscles featured by multineuronal innervation which is required to obtain maximum electrical and mechanical responses at least in fast muscles like adductors [22, 55, 67, 99, 102]. However in molluscs there are muscles (e.g. posterior jugalis, columellar and buccal retractor muscles of Helisoma) where no evidence for multineuronal innervation of individual muscle fibers was observed [40].

\section{THE ROLE OF GLUTAMATE AND ACETYLCHOLINE AS EXCITATORY NEUROTRANSMITTERS}

Subsequent upon polyneuronal innervation molluscan muscle fibers may receive dual excitatory innervation. The dual excitatory innervation has been observed at several neuromuscular contacts in gastropods [54, 99, 105]. For example, in Aplysia, the medial portion of the intrinsic buccal muscle ( $\mathrm{I} 3 \mathrm{~m})$ is innervated by two excitatory neurons, the glutamatergic B3 and the cholinergic B9 [43]. Neuromuscular transmission in molluscs appears to be mediated likely by ACh [25, 87, 97, 98]. In addition, glutamate (Glu) as an excitatory transmitter is also widely present in gastropods, where it has a functional role both at central synapses as well as at neuromuscular contacts $[3,13,22,23,26,53,69]$.

According to our physiological and immunohistochemical experiments FMs receive both cholinergic and glutamatergic excitatory innervation, meanwhile they lack an inhibitory one. Using a nerve-muscle preparation containing the olfactory nerve and the FM3 it has been revealed that nerve evoked contractions could well be simulated by short external ACh or Glu application. The difference between ACh- and Glu-elicited contractions was that the former long lasting with fast rising and slow declining phases and the latter was short with fast raising and declining phases. Both ACh- and Glu-elicited responses were successfully attenuated by cholinergic (mytolon, d-tubocurarine [d-TC], succinylcholine chloride [SCh]) or Gluergic (CNQX a potent AMPA, kainate antagonist) receptor antagonists, supporting the view that the excitatory neurotransmitters released from the nerve endings were ACh and Glu. Our assumption that part of the excitatory inputs in the FMs is cholinergic and/or glutamatergic was further supported by the observation that nerve evoked contractions were blocked either by cholinergic or glutamatergic receptor antagonists. The presence of the excitatory transmitters was further verified by immunohistochemistry using antibodies raised against the central type of choline acetyltransferase (ChAT) and different forms of vesicular glutamate transporters (VGlut). Positive immunoreactivity was detected in two or three relative thick bundles of axonal processes innervating the FM, forming a longitudinal arrangement along the muscle and giving extensive side 
branches, supporting a polyneuronal innervation. Polyneuronal innervation is important when muscle fibers do not generate propagated action potentials and activity of several motoneurons is necessary to induce full mechanical response. Another benefit of polyneuronal innervation is the possibility to release more than one excitatory transmitter and modulatory substances permitting fine regulation of the muscle [57]. Dual, AChergic and Gluergic excitatory innervation is not unique in the animal kingdom. Co-release of ACh and Glu as excitatory transmitters was already observed in developing tadpole spinal neurons, in basal forebrain neurons and in cortical afferents of rat $[1,7,63]$. Oblique and ring muscles of the body wall of an Onychophoran, Peripatoides noveazealandiae, are sensitive both to ACh and Glu and cytochemical staining verified the presence of the two transmitters in the muscles [89]. The tentacle of the slug Vaginula revealed two types of nerve endings both containing clear synaptic vesicles accompanied by granular vesicles [4]. In the FM co-localization and co-transmission of ACh and Glu have not been proven, however, it was observed that Glu evokes fast, while ACh evokes slow muscle contractions and the presence of both transmitters were demonstrated immunohistochemically [57]. Thus the dual excitatory innervation may contribute to the fine-tuning of contractions and force produced by the FMs needed for the complex tentacular movements during olfactory orientation.

\section{NICOTINIC ACETYLCHOLINE RECEPTORS CONTAINING FUNCTIONAL $\alpha 7$-LIKE SUBUNIT MEDIATE CONTRACTIONS OF FLEXOR MUSCLES}

Cholinergic receptors are usually described in terms of vertebrate muscle pharmacology as muscarinic and nicotinic types, respectively, a classification which does not necessarily apply to invertebrates, especially not to gastropods [85, 97, 99]. It has been demonstrated in a wide range that ACh released at different central synapses can mediate opposite (depolarizing and/or hyperpolarizing) synaptic action $[5,25,87$, 99]. Such an effect was caused by the presence of several types of receptor to the same transmitter on the membrane of a single cell $[5,44]$. In neurons of molluscs, one receptor subtype is linked to a chloride channel inducing hyperpolarization and the second receptor subtype is linked to an increased conductance of mixed cations inducing depolarization [60]. Pharmacological experiments performed in order to identify the receptor subtypes revealed the presence of at least three types of AChRs in Aplysia [45]. Two curare-sensitive-receptors responded like vertebrate nicotinic receptors to both cholinomimetics and cholinolytics. The third type showed a unique pharmacological profile because it was not affected by nicotine and muscarine either and could not be blocked by atropine and curare $[44,45]$.

At the neuromuscular contacts of different gastropod muscles ACh was found to be likely an excitatory transmitter [21]. Contrary, on the heart musculature of molluscs, including gastropods, ACh acted usually as an inhibitory transmitter [51]. The concept of different excitatory and inhibitory cholinergic receptor sites at the mem- 
brane of gastropod smooth muscles was also supported by findings which may explain the response variety to exogenously applied ACh [see 96].

However, only few studies have examined the detailed pharmacology of AChinduced responses and receptor subtypes present in various molluscan muscles. Moreover these studies gave a confusing picture of the pharmacological properties regarding the subtype of the cholinoreceptors present in the muscle [97]. Therefore, we examined in detail the pharmacology of the ACh receptors located at the possible sites of neuromuscular contacts of the FMs. To address this issue, first the pharmacological profile of the muscle AChR was characterized and the receptor subtype identified using molecular tools [49]. The effect of ACh on FMs of the superior tentacles was a slow and consistent tonic, concentration-dependent contraction with no phasic activity. The threshold to induce contraction was sufficiently low $\left(10^{-8}\right.$ and $\left.10^{-7} \mathrm{M}\right)$ to provide compelling evidence that $\mathrm{ACh}$ is an excitatory neurotransmitter at the neuromuscular contacts of FMs. At concentrations producing maximum contraction $\left(10^{-4} \mathrm{M}\right)$, repeated ACh application did not lead to a reduction in size of the response, demonstrating slow desensitization properties of the muscle AChRs. Using a broad spectrum of nicotinic and muscarinic agonists and antagonists, it was demonstrated that ACh-elicited contractions in the FMs are attributed to the activation of nAChRs that contain the $\alpha 7$-like subunit. Contractions could be evoked by nicotine, carbachol, $\mathrm{SCh}$, tetraethyl-ammonium chloride and the selective $\alpha 7-\mathrm{nAChR}$ agonist choline chloride and PNU-282987, and blocked by several nAChR selective antagonists, such as mytolon, hexamethonium, $\mathrm{SCh}, \mathrm{d}-\mathrm{TC}$, hemicholinium, decamethonium, $\alpha$-bungarotoxin $(\alpha \mathrm{BgTX})$ and $\alpha$-conotoxin IMI. The specific muscarinic agonist oxotremorine and arecoline failed to elicit contractions. At the same time, atropine, scopolamine, strychnine and levetimide effectively blocked the ACh elicited contractions, while the specific muscarinic antagonist orphenadrine did not. Based on these pharmacological properties a conclusion can be drawn that the AChRs of the FM are cation-permeable nicotinic receptors that contain the $\alpha 7$-like subunit and are sensitive to $\alpha \mathrm{CTX}-\mathrm{IMI}$ and $\alpha \mathrm{BgTX}$ and can be activated by nicotine and choline. Immunohistochemical detection confirmed the presence of $\alpha 7$ - or $\alpha 7$-like AChRs in muscle cells, and $\alpha 4-\mathrm{AChRs}$ in nerves innervating the muscle. The $\alpha 4$ subunit containing AChRs were detected in axons innervating the FMs, suggesting their involvement in possible feedback control of the ACh release from nerve terminals. Unfortunately, the Western blot (WB) experiments gave unequivocal results revealing several peptide bands in the range of $40-140 \mathrm{kDa}$. In the literature it is described that certain commercially available $\alpha 7$-antibodies lack specificity because they give the same immune response in wild-type and knockout mice although RNA analyses confirmed the disruption of the $\alpha 7$ allele and lack of $\alpha 7$ message in the knockouts [27, 70]. The unequivocal WB data were compensated by PCR experiments by which the presence and expression of the Lymnaea-type (LnAChRA) nAChR subunit was assessed. Pharmacological and immune data therefore were further supported by the presence of transcript in the FM coding for the LnAChR A subunit. The LnAChR A subunit is related to the homo-oligomeric human $\alpha 7 \mathrm{nAChR}$ and when expressed in oocytes it 
is activated by cytosine and nicotine and blocked by $\alpha \mathrm{BgTX}$, $\alpha \mathrm{CTX}$-IMI [94]. However the nAChR in the snail FMs desensitizes slowly and also conducts $\mathrm{Na}^{+}$ along with $\mathrm{Ca}^{2+}$, suggesting that the receptor is not a homopentamer [49]. In summary, it can be concluded that the slowly desensitizing $\alpha \mathrm{BgTx}$-sensitive responses obtained from FMs were produced by activation of $\alpha 7$-like AChRs. This is the first demonstration of an obligatory role for a functional $\alpha 7$-like $\mathrm{nAChR}$ in a peripheral organ of molluscs.

\section{SYNAPTIC MODULATION IS CRUCIAL FOR SPATIAL AND TEMPORAL COLLECTION OF INFORMATION}

We hypothesized that setting the appropriate movement of tentacles for environmental cues by neuronal modulation is important for the optimal accommodation of the whole organism to the environment [101]. Indeed, our study showed that monoamine- (5-HT, DA) and/or neuropeptide-mediated (FMRFa, PACAP) presynaptic facilitation or inhibition provides a mechanism to modulate both large scale and specific tentacle movements. A few studies on gastropods have been published describing the direct effect of 5-HT at neuromuscular contacts. The 5-HT evokes facilitation of the transmitter release or muscle relaxation acting pre- or postsynaptically. Such effects on muscle contraction and force may be dependent on 5-HT concentration and the species studied [100]. The 5-HT applied at low or high concentration $\left(10^{-8}\right.$ or $\left.10^{-5} \mathrm{M}\right)$ differentially modulated nerve and ACh elicited contractions of the FM. At high concentration 5-HT increased the amplitude of contractions elicited either by electrical stimulation or by external ACh application. In all FMs the integral of nerve evoked contraction was decreased showing that the relaxation phase is facilitated, thereby shortening the duration of the contraction suggested clearly a postsynaptic site of action. The postsynaptic site of 5-HT action was further confirmed by the observation that the relaxing phase of $\mathrm{KCl}$-elicited contraction was also accelerated in the presence of the 5-HT [59]. Contrary to the data obtained by 5-HT, DA was described to modulate thin (FM1, FM2) and thick (FM3) muscles in an opposite way, that is, contractions of the thin muscles were decreased, while those of thick muscle were increased following pretreatment with DA. The contraction parameters, the amplitude and integral changed parallel, suggesting presynaptic modulation. It is assumed that the opposite modulation by DA was due to an increased or decreased ACh release from presynaptic nerve terminals induced by activation of D1 or D2 receptors. Preliminary results obtained by immunohistochemistry seemed to support this conclusion since D1- and D2-like receptors were observed on axons but not on the muscle cells (L. Hernádi, unpublished data).

The widespread distribution of neuropeptides have been shown both in vertebrates and invertebrates where their roles were described as potent modulators of synaptic activity $[19,36,37,38,39,48,50,65,73,74]$. The neuropeptide signaling is functionally diverse as the same peptide may act as neurohormone, locally released neuromodulator and co-transmitter, respectively [74]. Whereas the actions 
of some neuropeptides appear to be restricted to the Helix CNS, others are more widely distributed in the periphery exerting their action at different peripheral organs. Using immunohistochemistry the presence of the wide variety of neuropeptides has been demonstrated in different peripheral organs including muscles in gastropods [15, 17, 20, 28, 30, 80]. The localization of FMRFa and PACAP-like peptides was also demonstrated in nerves innervating FM muscles of the snail, suggesting a regulatory role of these neuropeptides [56]. An interesting observation was that both peptides had no effect on the muscle tone, referring to a possible presynaptic action. It was, however, observed, that exogenous FMRFa inhibited the FM
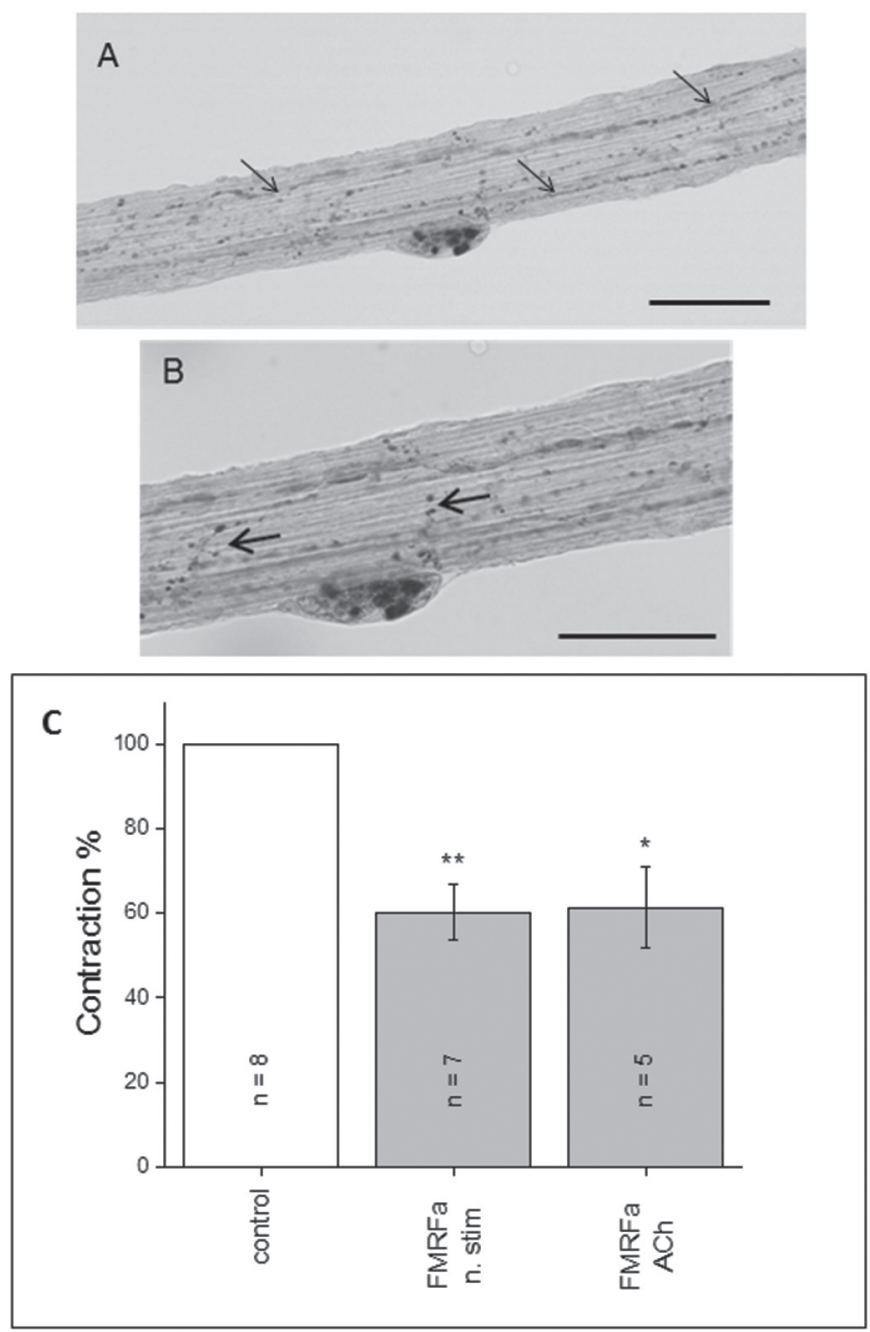

Fig. 2. A - FMRFa immunopositive nerve fibers (arrows) running longitudinally in the tentacle flexor muscle (M3) B - Enlarged detail is showing the transversal ramification of the labelled fibers. Scale bar: $100 \mu$. C - FMRFa $\left(10^{-6} \mathrm{M}\right)$ attenuates both stimulation and ACh $\left(10^{-5} \mathrm{M}\right)$ elicited contractions. Asterisks indicate a significant difference from the conrol value at $* \mathrm{p}>0.05,{ }^{* *} \mathrm{p}>0.01$ 
muscle contraction elicited either by nerve stimulation or by ACh (Fig. 2). The cellular mechanism of FMRFa effect on the FMs was not investigated in detail, because FMRFa receptors could not be identified so far. In vertebrates PACAP modulates the effects of transmitters at inhibitory smooth muscle neuromuscular junctions, where it elicits relaxation by increasing adenylate cyclase activity or by controlling smooth muscle mechanical activity. It acts directly on muscle cells via PACAP receptors or indirectly by stimulating NO synthesis [40, 61, 90, 104]. In order to determine whether the effect of PACAP was elicited through pre- and/or postsynaptic mechanisms on the FMs, the localization of PACAP and its receptors was assessed by immunohistochemistry. PACAP27-like and PAC1R-like immunoreactive nerve fibers were present throughout the muscles. Our experiments demonstrated that PACAP markedly potentiated contractions of the FMs of the upper tentacles evoked by synaptically released or by exogenously applied ACh [49, 58]. The effect of PACAP27 enhancing nerve-evoked contractions can be explained by (a) presynaptic mechanisms when PACAP27 binds to specific PAC1Rs leading to the increased release of neurotransmitter, (b) postsynaptic mechanisms, whereby PACAP27 facilitates excitation-contraction coupling of the muscle, or (c) pre- and postsynaptic mechanisms acting together. The data presented here suggest that PACAP27 is potentially able to increase synaptically elicited contraction by increasing the amount of ACh released at the neuromuscular contact. Only PAC1Rs, which are coupled via AC/PKA-mediated signal transduction, were required to enhance neuromuscular transmission indicating that cyclic nucleotides and cyclic-nucleotidedependent protein kinases are necessary components of the pathway that underlie presynaptic modulation by this peptide. However the enhancement of the AChevoked contraction by PACAP was observed both in normal and $\mathrm{Ca}^{2+}$-free solution, clearly showing that voltage dependent $\mathrm{Ca}^{2+}$ channels were not involved in PACAP induced $\mathrm{Ca}^{2+}$ release. Further on, the potentiating effect of PACAP on ACh-evoked contraction was still observed even when VGCCs were blocked by cadmium. The ratio of PACAP27-induced potentiation in $\mathrm{Ca}^{2+}$-free solution was almost the same as in solution of normal ion-content, supporting the conclusion that PACAP induced release of $\mathrm{Ca}^{2+}$ from intracellular stores. When ryanodine/caffeine sensitive $\mathrm{Ca}^{2+}$ release was inhibited by RR, the potentiating effect of PACAP27 was significantly blocked, suggesting that PACAP stimulated $\mathrm{Ca}^{2+}$-release from intracellular stores was mediated by PKC dependent pathway. Thus the possibility exists that PACAP may enhance muscle contraction not only by increased cAMP production, but also by mobilizing cytosolic $\mathrm{Ca}^{2+}$ concentrations [59]. Therefore, an alternative explanation would be a direct effect of PACAP on the muscle not requiring receptors. The PAC1R antibody used successfully on nerves innervating the FMs turned out to be ineffective to reveal the presence of PAC1Rs on the muscle cells.

In summary, a range of fine modulatory pathways influencing the tentacle muscles may provide a larger dynamic scale of responses which could be advantageous in sensing odors where precise spatial and temporal gain of information is critical for optimal performance. The increased or decreased sensitivity of muscles and innervating neu- 


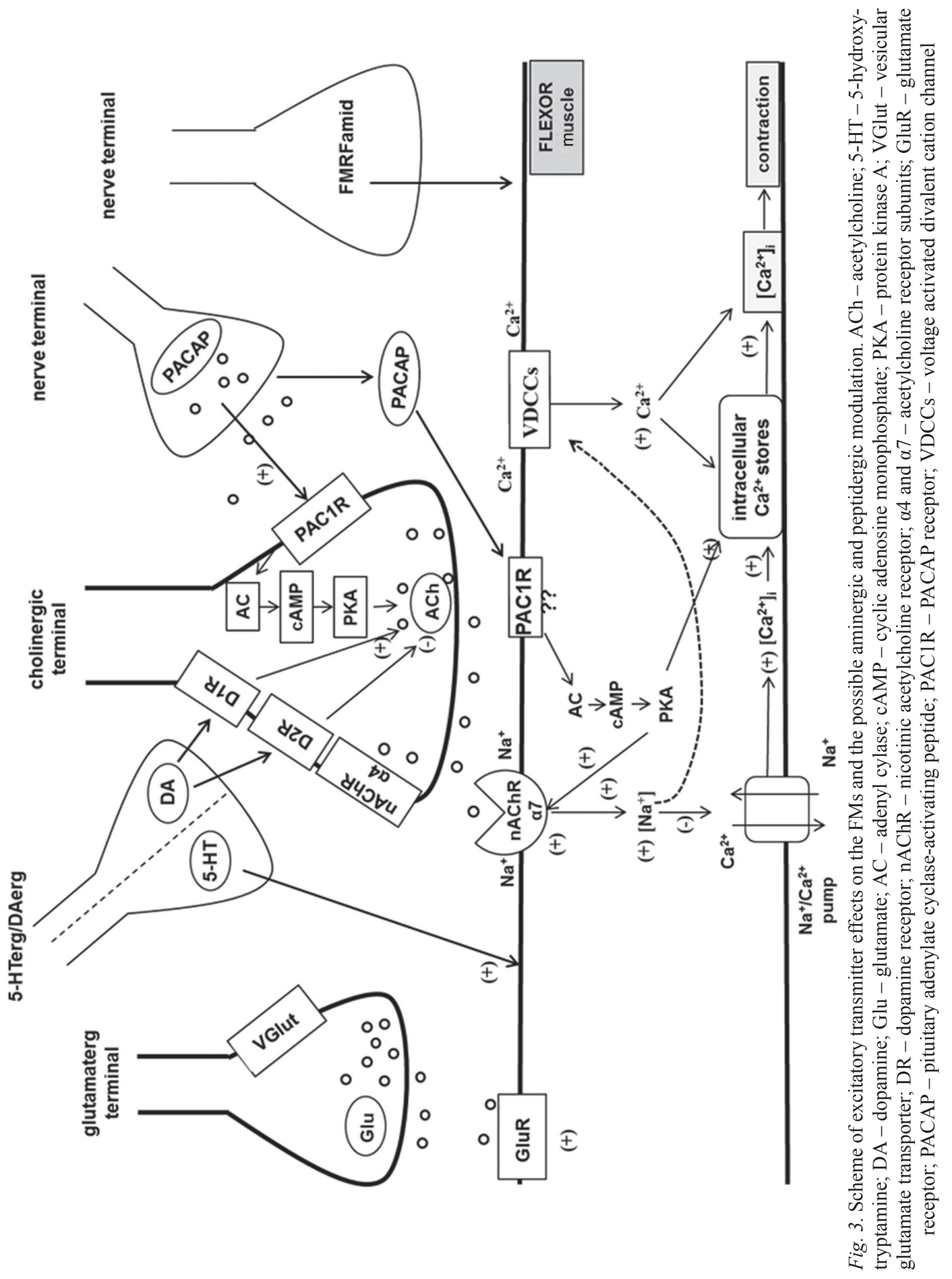

Acta Biologica Hungarica 67, 2016 
rons could be important for adjusting sensitivity of organism to environmental cues, which require an immediate behavioral response. The scheme shown in Fig. 3 summarizes the examined and suggested pathways of the neurotransmitters and modulators regulating the FMs.

\section{FLEXOR MUSCLES PLAY AN ESSENTIAL ROLE IN SPATIAL AND TEMPORAL ODOR INFORMATION COLLECTION}

The three-dimensional scanning movements of the tentacles during exploration of the environment is important to gain information concerning the occurrence and spatial location of the actual odor source. In case of an attractive odor, this involves a continuous bilateral comparison of the relative odor concentration on the two sides of the animal, followed by turning towards the side of higher concentration [10, 76]. Behavioral and physiological analyses predict substantially different functional roles for the muscles of tegumentum, TRM and FMs of the tentacles. The active snail continuously scans the environment and at a hint of danger withdraws its tentacles rapidly. The tentacle withdrawal is robust and the fastest movement among the entire snail's motor behaviors [8]. In case of most of the terrestrial snails the retraction is accompanied by inversion of the outer skin surfaces suggesting the participation both of tegumentum and the tentacle retractor muscles. Partial contraction of tentacle can be explained either by contraction of retractor muscle or by contraction of all three FMs. However, a tentacle movement around the basal pivot or the quiver according to our observation is exclusively associated with the contractions of FMs. One end of the tentacle FM is attached to the ventral side of the sensory pad along a fronto-caudal line with their other ends anchored to the base of the tentacle stem. The anchoring point arrangement of FMs at the base of the stem determines the three axes and force vectors in space along with separate or synchronous contraction of muscles are able to move tentacles in space. According to Peschel et al. [79], upper tentacles may have four basic positions during foraging: 1) the upright position during locomotion, 2) external lateral movements of upright tentacles, which is characteristic during exploration; 3) external lateral movement of downward tentacles, when conditioned odor is sensed, and 4) the forward horizontal position during approaching conditioned food. All these tentacle movements reasonable can be explained by contractions of different FMs. For example, the upright position is generated by contraction of the FM3 alone, while upright lateral movement is due to the synchronous contraction of the FM2 and FM3. Contraction of the FM2 and relaxation of the FM3 elicit downward position of tentacles, whereas the horizontal position is generated by the contraction of FM1 and FM2 [29, 31]. In summary, it is presumed that FMs are necessary and sufficient to perform all the tentacle movements around the basal pivot. It cannot be excluded, however, that parallel contractions of various regions of the tegumentum may assist to FMs to move around the basal pivot the upper tentacles. 
ACKNOWLEDGEMENTS

The authors are grateful to Dr. Z. Pirger for providing Fig. 1 and Dr. K. Elekes for FMRFa immunohistochemistry shown in Fig. 2. The work is funded byTÁMOP-4.2.2.A-11/1/KONV-2012-0024.

\section{REFERENCES}

1. Allen, T. G. J., Abogadie, F. C., Brown, D. A. (2006) Simultaneous release of glutamate and acetylcholine from single magnocellular "cholinergic" basal forebrain neurons. J. Neurosci. 26, 1588-1595.

2. Amsellen, J., Nicaise, G. (1976) Distribution of the glio-intestinal system in molluscs. II. Electron microscopy of tonic and phasic muscles in the digestive tracts of Aplysia and other opistobranchs. Cell Tissue, 165, 19-71-184.

3. Ascher, P., Nowak, L., Kehoe, J. S. (1986) Glutamate-activated channels in molluscan and vertebrate neurones. In: J. M., Ritchie, R. D., Keynes, L. Bolis (eds), Ion Channels in Neural Membranes. Alan R. Liss, New York, pp. 283-295.

4. Barrantes, J. F. (1970) The neuromuscular junctions of a pulmonate mollusc. I. Ultrastructural study. Z. Zellforsch. 104, 205-212.

5. Blankenship, J. E., Wachtel, H., Kandel, E. R. (1971) Ionic mechanisms of excitatory, inhibitory, and dual synaptic actions mediated by an identified interneuron in abdominal ganglion of Aplysia. $J$. Neurophysiol. 36, 76-92.

6. Brooks, D. D., Huddart, H., Lennard, R., Hill, R. B. (1990) Calcium utilization in contractures induced by acetylcholine or high-potassium saline in molluscan proboscis muscles. J. Exp. Biol. 149, 379-394.

7. Brown, D. A. (2010) Muscarinic acetylcholine receptors (mAChRs) in the nervous system: some functions and mechanisms. J. Mol. Neurosci. 41, 340-346.

8. Chase, R. (1986) Lessons from snail tentacles. Chemical Senses 11, 411-426.

9. Chase, R. (2002) Behavior and its Neural Control in Gastropod Mollusks. Oxford University Press, New York.

10. Chase, R., Croll, R. (1981) Tentacular function in snail olfactory orientation. J. Comp. Physiol. A143, 357-362.

11. Chase, R. A., Tolloczko, B. (1993) Tracing neural pathways in snail olfaction: from the tip of the tentacles to the brain and beyond. Microsc. Res. Tech. 24, 214-230.

12. Cottrell, G. A., Schot, L. P., Dockray, G. J. (1983) Identification and probable role of a single neurone containing the neuropeptide Helix FMRFamide. Nature 304, 638-640.

13. Dale, N., Kandel, E. (1993) L-Glutamate may be the fast excitatory transmitter of Aplysia sensory neurons. Proc. Natl Acad. Sci. USA 90, 7163-7167.

14. Elekes, K. (1978) Ultrastructure of synapses in the central nervous system of lamellibranch molluscs. Acta Biol. Acad. Sci. Hung. 29, 139-154.

15. Elekes, K. (2000) Ultrastructural aspects of peptidergic modulation in the peripheral nervous system of Helix pomatia. Microsc. Res. Tech. 49, 534-546.

16. Kiss, T., Elekes, K. (1972) Myo-neural junctions in the ventricle of the snail Helix pomatia. Acta Biol. Acad. Sci. Hung. 23, 207-209.

17. Elekes, K., Kiss, T., Fujisawa, Y., Hernádi, L., Erdélyi, L., Muneoka, Y. (2000) Mytilus inhibitory peptides (MIP) in the central and peripheral nervous system of the pulmonate gastropods, Lymnaea stagnalis and Helix pomatia: distribution and physiological actions. Cell Tissue Res. 302, 115-134.

18. Elekes, K., Kiss, T., S.-Rózsa, K. (1973) Effect of Ca-free medium on the ultrastructure and excitability of the myocardial cells of the snail Helix pomatia L. J. Mol. Cell. Cardiol. 8, 133-138.

19. Elekes, K., Ude, J. (1993) An immunogold electron microscopic analysis of FMRFamide-like immunoreactive neurons in the CNS of Helix pomatia: ultrastructure and synaptic connections. J. Neurocytol. 22, 1-13. 
20. Elekes, K., Ude, J. (1994) Peripheral connections of FMRFamide-like immunoreactive neurons in the snail, Helix pomatia: an immunogold electron microscopic study. J. Neurocytol. 23, 758-769.

21. Endean, R. (1972) Aspects of molluscan pharmacology. Chapter 13. In: Florkin, M., Scheer, B. T. (eds) Chemical Zoology. vol. VII. Mollusca. Academic Press, New York and London.

22. Fox, L. E., Lloyd, P. E. (1999) Glutamate is a fast excitatory transmitter at some buccal neuromuscular synapses in Aplysia. J. Neurophysiol. 82, 1477-1488.

23. Fox, L.E., Lloyd, P. E. (2002) Mechanisms involved in persistent facilitation of neuromuscular synapses in Aplysia. J. Neurophysiol. 87, 2018-2030.

24. Gelperin, A., Tank, D. V., Tesauro, J. (1989) Olfactory processing and associative memory: cellular and modelling studies. In: Byrne, J. H., Berry, W. O. (ed.) Neural Models and Plasticity. Theoretical and Empirical Approaches. Academic Press, Orlando, pp. 133-159.

25. Gerschenfeld, H. M. (1973) Chemical transmission in invertebrate central nervous systems and neuromuscular junctions. Physiol. Rev. 53, 1-119.

26. Hatakeyama, D., Aonuma, H., Ito, E., Elekes, K. (2007) Localization of glutamate-like immunoreactive neurons in the central and peripheral nervous system of the adult and developing pond snail, Lymnaea stagnalis. Biol. Bull. 213, 172-186.

27. Herber, D., Severance, E. C., Cuevas, J., Morgan, D., Gordon, M. (2004) Biochemical and histochemical evidence of nonspecific binding of a7 $\mathrm{nAChR}$ antibodies to mouse brain tissue. $J$. Histochem. Cytochem. 52, 1367-1375.

28. Hernádi, L., Erdélyi, L., Hiripi, L., Elekes, K. (1998) The organization of serotonin-, dopamine-, and FMRFamide-containing neuronal elements and their possible role in the regulation of spontaneous contraction of the gastrointestinal tract in the snail Helix pomatia. J. Neurocytol. 27, 761-775.

29. Hernádi, L., Kiss, T., Krajes, N., Teyke, T. (2014) Novel peripheral motor neuros in the posterior tentacles of the snail responsible for local tentacle movements. Invert. Neurosci. 14, 127-136.

30. Hernádi, L., Pirger, Z., Kiss, T., Németh, J., Márk, L., Kiss, P., Tamás, A., Lubics, A., Tóth, G., Shioda, S., Reglődi, D. (2008) The presence and distribution of pituitary adenylate cyclase activating polypeptide and its receptor in the snail Helix pomatia. Neuroscience 155, 387-402.

31. Hernádi, L., Teyke, T. (2012) Novel triplet of flexor muscles in the posterior tentacles of the snail, Helix pomatia. Acta Biol. Hung. 63, 123-128.

32. Hernádi, L., Teyke, T. (2013) Neuronal background of positioning of the posterior tentacles in the snail Helix pomatia. Cell Tissue Res. 352, 217-225.

33. Heyer, C. B., Kater, S. B. (1973) Neuromuscular system in molluscs. Amer. Zool. 13, 247-270.

34. Hill, R. B. (2001) Role of $\mathrm{Ca}^{+}$in excitation-contraction coupling in echinoderm muscle: comparison with role in other tissues. J. Exp. Biol. 204, 897-908.

35. Hill, R. B., Greenberg, M. J., Irisawa, H., Nomura, H. (1970) Electromechanical coupling in a molluscan muscle, the radula protractor of Busycon canaliculatum. J. Exp. Zool. 174, 331-348.

36. Holmgren, S., Jensen, J. (2001) Evolution of vertebrate neuropeptides. Brain Res Bull. 55, 723-735.

37. Hoyle, C. H. V. (1998) Neuropeptide families: evolutionary perspectives. Regul. Pept. 73, 1-33.

38. Hökfelt, Z., Broberger, C., Xu, Z.-Q. D., Segeyev, V., Ubink, R., Diez, M. (2000) Neuropeptides - an overview. Neuropharmacology 39, 1337-1356.

39. Ikeda, T., Minakata, H., Fujita, T., Muneoka, Y., Kiss, T., Hiripi, L., Nomoto, K. (1992) Neuropeptides isolated from Helix pomatia Part 1. Peptides related to MIP, buccalin, myomodulin-CARP and SCP. In: Yanaihara, N. (ed.), Peptide Chem. Proceedings of the 2nd Japan Symposium on Peptide Chemistry, ESCOM Science Publishers B.V., Leiden. pp. 576-578.

40. Imoto, A., Inoue, R., Tanaka, M., Ito, Y. (1998) Inhibitory NANC neurotransmission in choledochoduodenal junction of rabbits, - a possible role of PACAP. J. Autonom. Nerv. Syst. 70, 189-199.

41. Inoue, T., Murakami, M., Watanabe, S., Inokuma, Y., Kirino, Y. (2006) In vitro odor - aversion conditioning in a terrestrial mollusk. J. Neurophysiol. 95, 3898-3903.

42. Kater, S. B., Heyer, C., Hegmann, J. P. (1971) Neuromuscular transmission in the gastropod mollusc Helisoma trivolvis: Identification of motoneurons. Zeitschrift für vergleichende Physiologie 74, 127-139. 
43. Keating, C., Lloyd, P. E. (1999) Differential modulation of motor neurons that innervate the same muscle but use different excitatory transmitters in Aplysia. J. Neurophysiol. 82, 1759-1767.

44. Kehoe, J. (1972) Three acetylcholine receptors in Aplysia neurones. J. Physiol. 225, 115-146.

45. Kehoe, J., McIntosh, M. J. (1998) Two distinct nicotinic receptors, one pharmacologically similar to the vertebrate a7-containing receptor, mediate $\mathrm{Cl}$ current in Aplysia neurons. J. Neurosci. 18, 81988213 .

46. Kerkut, G. A., Lambert, J. D. C., Gayton, R. J., Loker, J. E., Walker, R. J. (1975) Mapping of nerve cells in the suboesophageal ganglia of Helix aspersa. Comp. Biochem. Physiol. 50A, 1-25.

47. Kiss, T. (1977) Electrical properties of the cardiac muscle cell membrane and its role in the excitationcontraction coupling. Acta Biochim. Biophys. Acad. Sci. Hung. 12, 291-302.

48. Kiss, T. (2011) Diversity and abundance: the basic properties of neuropeptide. G. Comp. Endocrinol. $172,10-14$.

49. Kiss, T., Krajcs, N., Pirger, Z., Hernádi, L. (2014) Nicotinic acetylcholine receptors containing the $\alpha 7$-like subunit mediate contractions of muscles responsible for space positioning of the snail, Helix pomatia L. tentacle. Plos One 9(10):e109538 doi:10.1371/journal.pone.0109538.

50. Kiss, T., Pirger, Z. (2006) Neuropeptides as modulators and hormones in terrestrial snails: their occurrence, distribution and physiological significance. Invertebrate Neuropeptides and Hormones: Basic knowledge and recent advances. Kerala, India: Transworld Research Network. pp. 75-110.

51. Kiss, T., S.-Rózsa, K. (1972) Effect of biologically active substances on the spontaneous electrical activity of the heart muscle cells of Helix pomatia L. Annal. Biol., Tihany, 39, 29-38.

52. Kjaer, M. (2004) Mechanical loading. Physiol Rev. 84, 649-698.

53. Klein, A. N., Weiss, K. R., Cropper, E. C. (2000) Glutamate is the fast excitatory neurotransmitter of small cardioactive peptide-containing Aplysia radula mechanoafferent neuron B21. Neurosci. Lett. 289, 37-40

54. Kobayashi, M., Muneoka, Y., Fujiwara, M. (1981) The modulatory actions of the possible neurotransmitters in the molluscan radular muscles. In: Rózsa, K. S. (ed.) Adv. Physiol. Sci., Vol. 2, Pergamon Press, Oxford and New York, pp. 319-337.

55. Kononenko, N. L., Zhukov, V. V. (2005) Neuroanatomical and immunocytochemical studies of the head retractor muscle innervation in the pond snail, Lymnaea stagnalis L. Zoology (Jena), 108, 217 237.

56. Krajes, N. (2015) Physiology and pharmacology of muscles regulating olfactory orientation of superior tentacles of Helix pomatia. PhD Thesis, Pécs.

57. Krajes, N., Hernádi, L., Elekes, K., Kimura, S., Kiss, T. (2014) Excitatory neurotransmitters in the tentacle flexor muscles responsible for space positioning of the snail olfactory organ. Invert. Neurosci. 14, 59-69.

58. Krajcs, N., Hernádi, L., Pirger, Z., Reglődi, D., Tóth, G., Kiss, T. (2015) PACAP modulates acetylcholine-elicited contractions at nicotinic neuromuscular contacts of the land snail. J. Mol. Neurosci. $57,492-500$

59. Krajes, N., Márk, L., Elekes, K., Kiss, T. (2012) Morphology, ultrastructure and contractile properties of muscles responsible for superior tentacle movements of the snail. Acta Biol. Hung. 63, 129-140.

60. Laurienti, P. J., Blankenship, J. E. (1999) Properties of cholinergic responses in isolated parapodial muscle fibers of Aplysia. Neurophysiol. 82, 778-786.

61. Lecci, A., Santicioli, P., Maggi, C. A. (2002) Pharmacology of transmission to gastrointestinal muscle Curr. Opinion. Pharmacol. 2, 630-641.

62. Lemaire, M., Chase, R. (1998) Twitching and quivering of the tentacles during snail olfactory orientation. J. Comp. Physiol. 182, 81-87.

63. Li, W.-C., Soffe, S. R., Roberts, A. (2004) Glutamate and acetylcholine corelease at developing synapses. Proc. Natl Acad. Sci. USA 101, 15488-15493.

64. Luchtel, D. L., Martin, A. W., Deyrup-Olsen, I., Boer, H. H. (1997) Gastropoda: Pulmonata, In: Harrison, F. W., Ruppert, E. (eds), Microscopic Anatomy of Invertebrates. Vol. 6B, Wiley-Liss, Inc. New York, pp. 459-718. 
65. Man-Son-Hing, H., Zoran, M. J., Lukowiak, K., Haydon, P. G. (1989) A neuromodulator of synaptic transmission acts on the secretory apparatus as well as on ion channels. Nature 341, 237-239.

66. Matsuo, R., Kobayashi, S., Yamagishi, M., Ito, E. (2011) Two pairs of tentacles and a pair of procerebra: optimized functions and redundant structures in the sensory and central organs involved in olfactory learning of terrestrial pulmonates. J. Exp. Biol. 214, 879-886.

67. Mellon, De. F. (1968) Junctional physiology and motor nerve distribution in the fast adductor muscle of the scallop. Science 160, 1018-1020.

68. Moore, P. A., Atema, J., Gerhard, G. A. (1991) Fluid dynamics and microscale chemical movement in the chemosensory appendages of the lobster, Homarus americanus. Chemical Senses 16, 663-674.

69. Moroz, L. L., Györi, J., Salanki, J. (1993) NMDA-like receptors in the CNS of molluscs. Neuroreport 4, 201-204.

70. Moser, N., Mechavar, N., Jones, I., Gochberg-Sarver, A., Orr-Urtreger, A., Plomman, M., Salas, R., Molles, B., Marubio, L., Roth, U., Muskos, U., Winzer-Serhan, U., Burgeois, J.-P., LeSourd, A.-M., De Biasi, M., Lindstrom, J., Maelicke, A., Changeux, J.-P., Wevers, A. (2007) Evaluating the suitability of nicotinic acetylcholine receptor antibodies for standard immunodetection procedures. J. Neurochem. 102, 479-492.

71. Motokawa, T. (1984) Connective tissue catch in Echinoderms. Biol. Rev. 59, 255-270.

72. Muneoka, Y., Twarog, B. (1983). Neuromuscular transmission and excitation-contraction coupling in molluscan muscle. In: Saleuddin, A. S. M., Wilbur, K. M. (eds) The Mollusca, Vol. 4, Academic Press, New York, pp. 3-4.

73. Muneoka, Y., Kobayashi, M. (1992) Comparative aspects of structure and action of molluscan neuropeptides. Experientia 48, 448-456.

74. Nassel, D. R. (2009) Neuropeptide signaling in invertebrates. Encyclopedia of Neuroscience 6, 821828 .

75. Nelson, I. D. (1994) The relation between excitation-contraction coupling and fine structure of a molluscan muscle, the radula retractor of the whelk, Buccinum undulatum. J. Comp. Physiol. 164, 229237.

76. Nikitin, E. S., Korshunova, T. A., Zakharov, I. S., Balaban, P. (2008) Olfactory experience modifies the effect of odour on feeding behavior in a goal-related manner. J. Comp. Physiol. 194, 19-26.

77. Nikitin, E. S., Zakharov, I. S., Samarova, E. I., Kemenes. G., Balaban, P. M. (2005) Fine tuning of olfactory orientation behaviour by the interaction of oscillatory and single neuronal activity. Eur. $J$. Neurosci. 22, 2833-2844.

78. Paniagua, R., Royuela, M., Garcia-Anchuelo, R. M., Fraile, B. (1996) Ultrastructure of invertebrate muscle cell types. Histol. Histopathol. 11, 181-201.

79. Peschel, M., Straub, V., Teyke, T. (1996) Consequences of food-attraction conditioning in Helix: a behavioral and electrophysiological study. J. Comp. Physiol. A, 178, 317-327.

80. Pirger, Z., Laszló, Z., Hiripi, L., Hernádi, L., Tóth, G., Lubics, A., Reglődi, D., Kemenes, G., Mark, L. (2010) Pituitary adenylate cyclase activating polypeptide (PACAP) and its receptors are present and biochemically active in the central nervous system of the pond snail Lymnaea stagnalis. J. Mol. Neurosci. 42, 464-471.

81. Plesch, B. (1977) An ultrastructural study of the innervation of the musculature of the pond snail Lymnaea stagnalis (L.) with reference to peripheral neurosecretion. Cell Tissue Res. 183, 353-369.

82. Prescott, S. A., Gill, N., Chase, R. (1997) Neural circuit mediating tentacle withdrawal in Helix aspersa, with specific reference to the competence of the motor neuron C3. J. Neurophysiol. 78, 2951-2965.

83. Rigon, F., Manica, G., Guma, F., Achaval, M., Faccioni-Heuser, M. C. (2010) Ultrastructural features of the columellar muscle and contractile protein analyses in different muscle groups of Megalobulimus abbreviatus. Tissue \& Cell. 42, 53-60.

84. Rogers, D. C. (1968) Fine structure of smooth muscle and neuromuscular junctions in the optic tentacles of Helix aspersa and Limax flavius. Z. Zellforsch. 89, 80-94.

85. Sakharov, D. A. (1970) Cellular aspects of invertebrate neuropharmacology. Annual Rev. Pharmacol. $10,335-352$.

Acta Biologica Hungarica 67, 2016 
86. Sanger, J. W., Hill, R. B. (1972) Ultrastructure of the radula protractor of Busycon canaliculatum. Z. Zellforsch. 127, 314-322.

87. S.-Rózsa, K. (1984) The pharmacology of molluscan neurons. Prog. Neurobiol. 23, 79-150.

88. Sugi, H., Suzuki, S. (1978) Ultrastructural an physiological studies on the longitudinal body wall muscle of Dolabella auricularia. I. Mechanical responses and ultrastructure. J. Cell. Biol. 79, 454466.

89. Stern, M., Bicker, G. (2008) Mixed cholinergic/glutamatergic neuromuscular innervation of Onychophora: a combined histochemical/electrophysiological study. Cell Tissue Res. 333, 333-338

90. Takeuchi, T., Yamazaki, Y., Negoro, T., Fujijami, K., Mukai, K., Fujita, A., Takewaki, T., Hata, F. (2004) Changes in mechanism of PACAP-induced relaxation in longitudinal muscle of the distal colon of Wistar rats with age. Regul. Pept. 118, 1-9.

91. Turner, M. B., Szabo-Maas, T. M., Poyer, J. C., Zoran, M. J. (2011) Regulation and restoration of motoneuronal synaptic transmission during neuromuscular regeneration in the pulmonate snail Helisoma trivolvis. 221, 110-125.

92. Twarog, B. (1976) The regulation and control in molluscan muscle. J. Gen. Physiol. 50, 157-169.

93. Twarog, B. M., Muneoka, Y. (1972) Calcium and the control of contraction and relaxation in a molluscan catch muscle. Cold Spring Harbor Symposium on Quantitative Biology 37, 489-504.

94. van Nierop, P., Bertrand, S., Munno, D. W., Gouwenberg, Y., Van Minnen, J., Spafford, J. D., Syed, N., Bertrand, D., Smit, A. B. (2006) Identification and functional expression of a family of nicotinic acetylcholine receptor subunits in the central nervous system of the mollusc Lymnaea stagnalis. J. Biol. Chem. 281, 1680-1691.

95. Wabnitz, R. W. (1976) Mechanical and electromyographic study of the penis retractor muscle (PRM) of Helix pomatia. Comp. Biochem. Physiol. A, 55, 253-259.

96. Wabnitz, R. W. (1976) A dual effect of acetylcholine on gastropod smooth muscle preparations. Z. Naturforsch. 31, 730-731.

97. Walker, R. J., Holden-Dye, L. (1991) Evolutionary aspects of transmitter molecules, their receptors and channels. J. Exp. Biol. 102, Suppl., S7-S29.

98. Walker R. J. (1986) Transmitters and modulators. In: Willows, A. O. D. (ed.) The Mollusca. Neurobiology and Behavior. 9, part 2 Academic Press, Orlando, pp. 279-485.

99. Walker, R. J., Brooks, H. L., Holden-Dye, L. (1996) Evolution and overview of classical transmitter molecules and their receptors. Parasitology 113, S3-S33.

100. Wu, W.-H., Cooper, R. L. (2012) Serotonin and synaptic transmission at invertebrate neuromuscular junctions. Exp. Neurobiol. 21, 101-112.

101. Worden, M. K. (1998) Modulation of vertebrate and invertebrate neuromuscular junctions. Neurobiol. 8, 740-745.

102. Yoshida, M., Kobayashi, M. (1991) Neural control of the buccal muscle movement in the african giant snail Achatina fulica. J. Exp. Biol. 155, 415-433.

103. Zakharov, I. S. (1994) Neuronal mechanisms of the organization of behavior. Avoidance behavior of the snail. Neurosci. Behav. Physiol. 24, 63-69.

104. Zizzo, M. G., Mulé, F., Serio, R. (2004) Interplay between PACAP and NO in mouse ileum. Neuropharmacology 46, 449-455.

105. Zoran, M. J., Haydon, P. G., Matthews, P. J. (1989) Aminergic and peptidergic modulation of motor function at an identified neuromuscular junction in Helisoma. J. Exp. Biol. 142, 225-243. 